\title{
FILOSOFÍA..., ¿PARA QUÉ?
}

Fernando Tinajero*

Je ne dirai rien de la philosophie, sinon que, voyant qu'elle a été cultivée par les plus excellents esprits qui aient vécu depuis plusieurs siècles, et que néanmoins il ne s'y trouve encore aucune chose dont on ne dispute [.......], je réputais presque pour faux tout ce qui n'était qui vraisemblable.

Descartes, Discurso del Método

Un pedido tan gentil como inexplicable me ha hecho regresar sobre un tema que, hace ya algunos años, creí haber abandonado para siempre: el tema, elemental y complejo al mismo tiempo, de la enseñanza de filosofía. Está por demás decir que mi primera reacción fue la de negarme a tan inesperada invitación, y estaba seguro de que para hacerlo me sobraban motivos - verdaderos motivos-, no pretextos. No obstante, algo que todavía no alcanzó a comprender me movió a rehusar la propuesta,

* Fernando Tinajero estudió filosofía en la Universidad Central del Ecuador, y más tarde en París y Praga. Enseñó filosofía hace algunos años, pero su dedicación principal ha sido a la literatura y la cultura ecuatoriana. Ha dictado cursos sobre estas materias en varias universidades del Ecuador y del extranjero. Es autor de varios libros de ensayo sobre la cultura ecuatoriana y de una novela que ha sido varias veces reeditada. Asegura que todavía no ha comenzado su obra. 
con una cortesía que en realidad era tibieza, en una carta cuyo texto expresaba — como quien deja una puerta, apenas entreabierta - la remota posibilidad de aceptar. Y al final, claro, acepté, como lo prueba el hecho de estar ahora mismo redactando estas líneas sin tener en realidad ninguna idea clara sobre lo que se espera de ellas.

Enseñar filosofía... Supongo que apenas se pronuncian estas palabras, las buenas almas que han nacido con la vocación de un magisterio tan extraño - yo también la tuve en mis comienzos - sienten el despertar de aquellas cuestiones que suelen quitar el sueño a los maestros: ¿cómo enseñar filosofía? ¿cómo hacer accesible el planteamiento de esas apasionantes cuestiones abstractas, cuyo solo enunciado provoca casi siempre unas incómodas miradas de sorpresa o compasión? ¿se trata de transmitir un saber ya elaborado, o de crear las condiciones para elaborarlo en un proceso solidario, que nivele al docente y sus pupilos? En otras palabras, ¿se trata de enseñar lo que han pensado los filósofos, de estimular a los jóvenes para pensar por su cuenta..., o se trata de ambas cosas? ¿en qué momento es más oportuno emprender esta tarea...?

Lo primero que debe tomarse en cuenta es que estas preguntas, y todas las que se les parecen, no son preguntas propiamente filosóficas, sino pedagógicas, o quizá solamente didácticas, puesto que su acento no recae en la filosofía sino en el cómo de la enseñanza. Más aún, son preguntas que presuponen que la filosofía puede ser enseñada, y además, que debe serlo. Pero... ¿es así en realidad?, ¿alguien se ha tomado la molestia de probarlo? Y si alguien lo ha hecho, ¿la suya ha sido una demostración de valor incuestionable, de esas que se dicen de una vez y para siempre, o es la expresión del respeto a una práctica tradicional, o apenas una simple opinión arbitrariamente elevada a la dignidad de un axioma? Lo que está en juego, por lo tanto, es un problema que se desdobla en dos preguntas: la pri- 
mera se refiere a la factibilidad de un hecho; la segunda, a su necesidad.

Estas son las preguntas cuya respuesta quisiera intentar en estas líneas; y si, como dice Simmel (Hauptprobleme..., I) lo que es la filosofía solo puede ser determinado desde la filosofía misma, supongo que debería tomarlas como preguntas filosóficas, puesto que, en cualquier caso, las posibles respuestas dependen en última instancia de lo que se conciba como filosofía. Sin embargo, no estoy seguro de que así sea: para mí, siguen siendo preguntas pedagógicas y así las tomo.

\section{1. ¿Es posible enseñar Filosofía?}

Decía mi maestro: pensar es deambularde calle en calleja, De calleja en callejón, hasta dar en un callejón sin salida.

Llegados a este callejón pensamos que la gracia estaría en salir de él. $Y$ entonces es cuando se busca la puerta al campo.

Antonio Machado, Juan de Mairena

A primera vista, esta extraña pregunta — de la cual es probable que muchos maestros ya se hayan olvidado- es una pregunta sin sentido. Así como el griego decía que el movimiento se demuestra andando, el hecho de que se haya enseñado filosofía en todas las escuelas de Occidente, desde hace por lo menos quince o veinte siglos, parecería demostrar de manera inobjetable que una tal enseñanza es indudablemente posible. Más aún, la historia de la cultura de Occidente no puede prescindir de esta enseñanza, que durante mucho tiempo fue la enseñanza misma, la que lo era por antonomasia, la enseñanza hacia 
la cual debían conducir necesariamente los primeros estudios de Gramática, Retórica y demás: solo la enseñanza del filosofar de los antiguos podía ser considerada como enseñanza de verdad, y nadie podía preciarse de haberse educado si ignoraba cada uno de los pasos de Platón en el Teeteto o el Sofista.

Parodiando a Machado, esto es, sin embargo, lo que yo entendería como "deambular por las calles de la ciudad”. No, desde luego, como el flâneur del que se ocupaba Benjamin, sino como el ordenado oficinista que sigue siempre el mismo recorrido a las mismas horas, alejado de riesgos y sorpresas, convencido de que no dejará de llegar al lugar de su destino. Ahí está la calle, bien trazada y con sus aceras bien dispuestas; allí están los semáforos que le liberan de decidir cuándo avanzar y cuándo detenerse; allí están los policías, no afectados aún de corrupción, solícitos y firmes, como una garantía tranquilizadora.

Cuando yo era muchacho, los primeros cursos de filosofía que me vi obligado a recibir no iban muy lejos del tranquilo andar de ese imaginario oficinista. Recorría por las anchas avenidas del pensar de los antiguos o modernos, en cuyos vericuetos no podía extraviarme: ahí estaba el libro que usaba, con sus renglones paralelos bien trazados, sus páginas numeradas, sus parágrafos y capítulos claramente ordenados, sus índices y notas... Puesto que su autor debió ser un maestro como el mío —aunque más competente-, yo sabía que sus dudas y preguntas no eran más que un ritual; sabía también que los filósofos de quienes hablaba con pretenciosa suficiencia acaso fueron atravesados por ese escalofrío que me recorría el cuerpo cuando yo tenía miedo, pero también sabía finalmente que en este caso se trataba de su miedo, no del mío. Para mí, las aporías y problemas eran solo una representación convencional. Hacía como si dudara con Descartes; como si persiguiera la "cosa en sí" 
con Kant; como si viviera con Hegel las desventuras de la conciencia; como si experimentara con Sartre la angustia de la nada...; pero no dudaba ni perseguía ni vivía ni experimentaba: había escuchado al maestro y leído las lecciones, siempre preguntándome si no sería más provechoso para mi vida que me enseñaran a hacer frente a esa extraña turbación que me enrojecía el rostro cuando veía una muchacha que se cruzaba conmigo todas las mañanas para ir a su colegio, que estaba a dos cuadras de mi casa. Si hubiese nacido unos años más tarde, ya no me habría causado turbación alguna la muchacha porque habría empezado enseguida a enamorarla sin necesidad de que mediara ninguna presentación formal; pero quizá me hubiera preguntado por qué no me enseñaban a detener una hemorragia, hacer una instalación eléctrica o cocinar unos frejoles, en lugar de enseñarme algo tan inútil como la filosofía. Pero no tenía remedio: por la gracia de mi nacimiento - gracia en la cual yo no tenía parte alguna - estaba llamado a ser doctor algún día, y nunca lo sería si no sabía de memoria las nueve categorías de Aristóteles, las cuatro reglas del método cartesiano y los cuatro conflictos de las ideas trascendentales. Es decir, estaba obligado a caminar por las calles conocidas, a respetar los semáforos, a prestar atención al policía, y lo hacía con la tranquilidad de quien sabía que llegaría a su destino, sin que en ese saber hubiera lugar para la duda. Peor todavía: cuando al elegir una carrera, hice de esa misma enseñanza mi propia profesión.

Felizmente, hace ya algunos años que dejé de enseñar filosofía. Tengo la impresión de que en los tiempos en que lo hacía por oficio mi tarea no llegó a ser muy diferente de la que desempeñaban los que fueron mis maestros: hacía el papel de transmitir las dudas y experiencias de otros, y además esperaba que mis aburridos alumnos hicieran luego la comedia de dudar y experimentar. A veces 
pensaba si podría torcer ese camino, arriesgarme, provocarles para así emprender con ellos una aventura diferente, pero el fracaso que me salió al encuentro varias veces me hizo comprender que una aventura ni se enseña ni se aprende. A veces, es verdad, me encuentro con algunos de los que fueron mis alumnos y les escucho decir que mis clases fueron importantes en sus vidas: no les creo. Les sonrío con simpatía y aprecio mucho su esfuerzo por hacerme creer que aquellas remotas clases no fueron tan inútiles... Yo sé, sin embargo, que lo fueron.

Porque si enseñar filosofía es como deambular por la ciudad, siguiendo siempre la ruta conocida, no hay que olvidar que toda ciudad es engañosa, aunque nunca lo sabremos si no nos detenemos a mirar alguna vez para ese costado que no teníamos la costumbre de mirar. Jamás lo hacemos si estamos junto a otros, y menos si somos conducidos por un guía — menos aún, mucho menos, si alguien quiere presionarnos para hacerlo. Incluso al estar acompañados llegamos cuando más a mirar de reojo, guardándonos para otro día la tentación de explorar más allá de la ruta conocida. Lo fascinante de toda exploración es hacerla en solitario, como aquel arriesgado aventurero que se atreve a desafiar las más altas montañas. La atractiva apariencia de alguna calleja aún no recorrida nos tienta con su promesa de algún descubrimiento inesperado; echamos a andar diciéndonos a nosotros mismos que al cabo de dos cuadras volveremos a la calle segura y familiar, y seguimos deslumbrados por el aspecto novedoso de las casas, las puertas y los balcones, sin advertir que la calleja se prolonga sin ser atravesada por ninguna otra, sin cuadras que hayan sido medidas a cordel, sin esquinas de referencia, sin letreros, y cuando menos lo pensamos hemos desembocado ya en un callejón cuyo aspecto inesperado nos atrae y atemoriza al mismo tiempo, despertando en nosotros una curiosidad irreprimible que tiene algo de morbo, algo de 
transgresión y de eso que los cristianos bautizaron con el feo nombre de "pecado"... Hasta cuando descubrimos que no hay salida; que no se puede avanzar; que hemos llegado a un cul-de-sac cuando ha caído la noche. Es entonces cuando queremos "hacer la gracia" de salir, saltar vallas y atravesar jardines silenciosos y ajenos, violar propiedades y traspasar los muros. Si alguna vez lo logramos terminaremos en el campo, en plena noche, sin caminos, sin estrellas en el cielo, solos con nosotros mismos.

En mi experiencia personal, ninguna clase dictada o recibida ha podido ofrecerme una aventura semejante. Todas, inclusive las que pude recibir en lugares lejanos de parte de maestros insignes, fueron el mismo deambular del oficinista en la ciudad. Muchas veces, es verdad, me sentí como quien debe internarse en las calles de alguna ciudad desconocida; pero ahí estuvieron siempre los libros, dispuestos a que yo los consultara tal como en los viajes consultaba esos planos donde estaban marcadas las rutas del transporte, las estaciones principales, las iglesias, los museos, las salas de concierto y otros monumentos. Si alguna vez llegué a descubrir algo, esos descubrimientos nunca fueron una real y auténtica aventura: fueron como ejercicios de una gimnasia mental cuyos únicos beneficios quizá hayan sido la adquisición de cierta habilidad para relacionar los objetos con sus signos, o tal vez un probable desarrollo de la costumbre de someter todas las cosas a un proceso inquisitivo y racional que, sin embargo, hizo que el mundo fuera ante mis ojos seco y frío, exactamente como un teorema euclidiano. En una palabra, los únicos beneficios que me ofrecieron ciertos descubrimientos apócrifos fueron de tal naturaleza que bien podía habérmelos proporcionado une indagación científica... con la ventaja de que las investigaciones de tal género, sí permiten aumentar el saber. 
El pensamiento, el verdadero pensamiento, aquel que tiene más probabilidades de ser considerado como filosófico, me fue dable alcanzar en pocas circunstancias, y nunca debido al acicate de ningún filósofo o doctrina. Aquella aventura imaginaria, capaz de trasladarme repentinamente a la inhóspita soledad que se extiende más allá de la ciudad; esa aventura que es propiamente el comienzo del pensar, difícilmente puede llevarse a cabo en el seno de lo que suele identificarse como la filosofía - aunque nada me autoriza a decir que ello no sea posible. Me ha ocurrido en cambio $-\mathrm{y}$ puede ocurrirle a cualquiera- al escuchar un adagio de Bach o de Beethoven, al intuir la presencia absoluta del vacío, al sentir el peso de una culpa insoportable, al darme de bruces con la áspera realidad de la miseria, al leer por enésima vez un poema olvidado: es entonces cuando he encontrado la posibilidad de un filosofar que no existe para ser escrito ni expuesto oralmente ante nadie, sino para preguntarme en mi interior por mí mismo y mi destino.

No se crea, sin embargo, que estoy hablando de una experiencia estética, tal como ella es descrita por Borges en el soberbio párrafo final de "La muralla y los libros". Nada de eso. Hablo de la experiencia del pensar, tal como aquella que fue vivida por Descartes en la noche del 10 de noviembre de 1619, cuando adquirió, en medio de un entusiasmo inflamado, la intuición de que existe un acuerdo fundamental entre las leyes de la naturaleza y las de la matemática - ese acuerdo del que habría de ocuparse en su famoso Discurso de 1637; hablo de aquella otra que fue vivida por Pascal en la noche del 8 de noviembre de 1654, cuando se desbocaron los caballos que tiraban su carroza $y$ al caer al Sena dejaron suspendido al pasajero en los restos del pretil, permitiéndole contemplar la muerte cara a cara- lo cual le impulsó a abandonar la ciencia y la vida mundana para dedicar el resto de su breve vida a las meditaciones que se reunieron luego en sus Pensamientos; hablo 
también de la intuición a la que Kant se refiere en una carta del 7 de junio de 1771, cuando anuncia su propósito de escribir hasta el invierno de aquel año un breve trabajo sobre los límites de la sensibilidad y la razón —aquel "breve trabajo" que de plazo en plazo le ocupó durante los diez años siguientes, y apareció al fin bajo el título de Crítica de la razón pura... Hablo, en una palabra, de experiencias que no pertenecen al género de la emoción estética ni al arrebato místico, sino al más genuino pensar, a ese pensar que, en buena parte ha configurado los caracteres de la modernidad occidental.

Entonces vuelvo a preguntarme: ¿es posible enseñar filosofía? Sí, desde luego, siempre que por filosofía se entienda lo que han pensado los filósofos, lo que se ha comentado sobre ellos, las relaciones que han establecido su pensamiento con otras formas de la cultura de su tiempo, con la evolución de la estructura social y política, con el movimiento general de la sociedad... Sospecho, sin embargo, que un estudio semejante - que se parece mucho al de la historia de la ciencia o la cultura-, suele conducir con más frecuencia a la erudición que a la comprensión general del pasado y del presente. Y, para decirlo de una vez, si no conduce a esa comprensión, no pasa de ser una pérdida de tiempo. No obstante, si por filosofía entendemos una actitud radical del espíritu en la cual cada uno se ve obligado a buscar el saber fundamental y debe enfrentarse sin disfraces ni dioses con su propio destino para elegir lo que hace de sí mismo y del mundo, entonces la filosofía es incomunicable.

En una palabra: lo que se puede enseñar, no siempre vale la pena; lo único que vale siempre es precisamente lo que no se puede enseñar. 


\section{2. ¿Es necesario enseñar filosofía?}

...el interés injustificado [en la filosofía]

es frívolo, es inauténtico, es

—digámoslo crudamente - falso. ¿Por qué se ha de hacer filosofía?

¿No hay otras cosas más urgentes?

El único modo de que la

filosofía sea efectiva

es haber llegado a ella; quiero decir,

no haber tenido más remedio que llegar,

haberla necesitado.

Julián Marías, Introducción a la Filosofía

Si lo que vale la pena no se puede enseñar, mal haría en decir que estudiar filosofía sea necesario. No obstante, he admitido que puede enseñarse filosofía como se enseña cualquier disciplina histórica; es decir, buscando las articulaciones que el pensamiento filosófico tiene con el desarrollo de la ciencia, de la literatura o del arte, con las concepciones del Estado y las justificaciones del poder político, e incluso con las cambiantes estructuras de la economía y la sociedad. Un ejemplo remarcable de un estudio semejante es el libro de Jaime Labastida sobre la relación entre la filosofía, la ciencia y la producción desde el siglo XVII hasta el XIX; otro, la ya clásica historia de la cultura griega escrita por Nestlé. Si alguien opta por esta alternativa debe tener plena conciencia, sin embargo, de que los objetivos que le será dable alcanzar no son distintos de los que podría proponerse un buen curso de historia, es decir, uno que no se limite a la sucesión de batallas, reyes, presidentes o modificaciones de los mapas, sino que se ocupe de lo que es más importante en cualquier historia: la evo- 
lución de las formas que asume el espíritu humano y de sus modos de expresarse.

Considero, por lo tanto, que aquellos cursos en los cuales se privilegia una visión sistemática de problemas en desmedro de los enfoques históricos están condenados casi siempre al fracaso. No diría esto en Francia, donde el racionalismo cartesiano impera en todas partes, sin excluir los chismes de las temibles concièrges: todavía guardo gratitud al texto de Simon Laval, cuyo curso de Filosofía General me sigue pareciendo una de las mejores iniciaciones en el pensamiento filosófico. Pero en el Ecuador, aunque ese tipo de cursos parece haber prevalecido en la enseñanza media, solo por excepción - y casi siempre debido a la mediación de otros estudios - es posible encontrar personas que tengan una idea clara de las corrientes de pensamiento que se han originado en el esfuerzo por dar respuesta a los "problemas de la filosofía". Lo más frecuente es que tales problemas sean vistos como algo del todo irrelevante, y que frente a las cuestiones trascendentales que preocuparon a los filósofos la mayoría tenga opiniones condicionadas por la tradición, el prejuicio o el lugar común. Es habitual oír que se atribuye las más vulgares connotaciones a palabras como "idealismo", "materialismo" o "positivismo", sin sospechar siquiera que esos son los nombres de fundamentales corrientes del pensamiento filosófico; y simultáneamente, es absolutamente raro que alguien aborde filosóficamente los problemas concretos de nuestra realidad histórica, social y política. Hay profesionales, desde luego, que suelen escribir para la prensa, y adoptan con frecuencia poses de solemnes pensadores; por desgracia, sus columnas no pasan de ser la caja de resonancia de autores extranjeros.

Con esto me parece haber dicho todo; creo conveniente agregar, sin embargo, dos observaciones: la primera se refiere a las posibles ventajas del estudio de ca- 
rácter histórico; la segunda, a la oportunidad de un curso semejante.

En relación con lo primero, mi experiencia me ha enseñado que el planteamiento mondo y lirondo de los llamados "problemas filosóficos" suele provocar la impresión de que los filósofos han sido siempre unos seres extraños, desligados del mundo y abstraídos en la búsqueda de ideas que no tienen vinculación alguna con la vida ni con el mundo real. Y así será siempre, de manera inevitable, para cualquiera que no haya estudiado profundamente las ciencias hasta llegar a tropezar con los problemas. Si a un muchacho que cursa el bachillerato se le pregunta de buenas a primeras qué es el Ser en general, la reacción más probable es una mirada desconcertada, frecuentemente acompañada de la sospecha no confesada de que el profesor que le hace semejante pregunta se encuentra enfermo. Y los más audaces pueden creerle loco o idiota si más adelante pregunta a sus alumnos: “es posible conocer?”, como si los muchachos no estuviesen adquiriendo cada día algún conocimiento nuevo. Bueno será, por consiguiente, que tanto el profesor como el alumno se ahorren el mal rato, y que sean capaces de transformarlo en un momento constructivo dedicando su atención a otra cosa: otra cosa que bien podría ser el manejo del lenguaje, que es una de las mejores maneras de aprender la lógica práctica $-\mathrm{y}$ conste que no hablo de las formas avanzadas de la lógica, que suelen encontrarse más cerca de la matemática que del lenguaje natural.

Esto significa que es conveniente llenarse de coraje para suprimir de una vez una asignatura tan inútil que solo contribuye a recargar los programas de bachillerato, y a esto se refiere la segunda de las observaciones anunciadas. Las visiones de carácter histórico, si todavía quieren conservarse, deberán serlo en niveles superiores, cuando las demás necesidades de la educación hayan sido cubier- 
tas y con la clara conciencia de que no se enseña un saber objetivo e insustituible, y mucho menos el pensar como experiencia radical, sino una interpretación -relativa como todas las interpretaciones históricas; una interpretación, repito, de las relaciones que el pensar de los filósofos tuvo en cada época con las demás expresiones de la cultura. No descarto, por supuesto, que en los cursos más avanzados de física o biología se presenten por sí mismos ciertos problemas que rebasan el horizonte propiamente científico; pero es obvio que éstos serán siempre los casos de excepción.

Pero entonces, ¿cuándo se necesita la filosofía? ¿cuándo se llega a ella? ¿cuándo puede decirse que no existe más remedio que entrar en la filosofía, si sabemos ya que ella no es capaz de darnos conocimientos verdaderos, sino apenas esos que Descartes llamaba "verosímiles"? Para unos, ese momento llega en el tramo final del bachillerato; para otros, al comenzar los cursos universitarios de pregrado. Para mí, solo hay dos situaciones en que, pese a todo, esa necesidad aparece: a la primera me he referido ya, y es aquella en que ciertos estímulos, que no son los mismos para todos, nos obligan a enfrentarnos con nosotros mismos. Se trata de una situación para la cual no hay momentos apropiados ni edades privilegiadas; lo mismo puede ocurrir en la adolescencia o la vejez, o "en medio del camino de la vida”. Entonces es importante que el espíritu no se pierda en vanas abstracciones ni se deje aprisionar por los fantasmas de la imaginación, y entender que todo monólogo interior -o "diálogo" consigo mismo, si se quiere- es siempre la internalización de un diálogo social; si no lo tenemos bien claro, acabamos consiguiendo que el Yo le diga a la conciencia lo que ella de antemano quiere oír.

La segunda situación - la única que tiene una relación, aunque indirecta, con el currículo de los estudios regulares - es aquella que se presenta cuando la suma de saberes distintos amenaza con la imagen de una totalidad 
fragmentada o caótica. Es entonces cuando hace falta un principio ordenador que haga visibles las internas conexiones de los fragmentos diversos: cómo las tendencias artísticas presentan una real correspondencia con el estado de la ciencia; cómo la literatura expresa la vigencia de las ideologías; cómo ellas se compaginan con una forma concreta de la economía y la organización social; cómo esas mismas formas dependen o son configuradas por los niveles de la ciencia. Dudo mucho que esta situación se presente en el bachillerato o al comenzar los estudios universitarios, puesto que solo se puede llegar a ella cuando se ha alcanzado un conocimiento más que inicial de muchas disciplinas. Me inclino más a pensar que se trata de una situación que puede aparecer cuando se ha avanzado ya lo suficiente como para tener, por encima de la particularidad de una ciencia, una visión de conjunto del universo del saber y del mundo real; es decir, hacia el final de los estudios de posgrado, siempre que sean estudios de verdad y no como muchos de los que se estilan hoy en el Ecuador, convertido en víctima de una desaforada competencia por los títulos, y no por los saberes.

En mi experiencia, sin embargo, casi nunca la filosofía ha sido enseñada de ese modo, o sea, después de haber llegado a ella, después de haber sentido su necesidad. Es muy frecuente que el maestro de filosofía quiera inconscientemente compensar su desventaja frente a los colegas que enseñan las ciencias, y lo hace esforzándose por rodear al contenido de su enseñanza de un halo de pretendida superioridad, cuya naturaleza siempre se presenta nebulosa. Habla de la relación de la filosofía con las ciencias como si se tratase de una competencia - con ventaja para la filosofía, desde luego; casi siempre ignora por completo la literatura y las artes y no es muy frecuente que conozca algo de la historia de las religiones o de la teología católica, muy necesaria para quien maneja ideas en el seno de una cul- 
tura que se ha configurado con una indiscutible preponderancia del cristianismo católico romano. He conocido profesores de filosofía para quienes el marxismo ha sido lo único digno de ser enseñado y suponen estar enseñándolo, aunque en realidad solo introducen a sus alumnos en un positivismo muy cercano a algunas formas del pensamiento burgués. He conocido también profesores de filosofía - más bien predicadores - que dicen profesar el cristianismo y suponen estar enseñándolo, aunque no pasan de reproducir prejuicios y lugares comunes más próximos al fariseísmo que a la genuina predicación de Jesús.

Pero he conocido también, y eso me consuela, $\mathrm{C}^{51}$ profesores de filosofía que hacían bien su papel y lograban que sus alumnos adquiriesen una visión muy amplia del proceso cultural de Occidente, luego de haber descubierto la trabazón interna de cada una de las configuraciones culturales y de todas ellas en conjunto. Entendían, por ejemplo, por qué los grandes sistemas filosóficos, como ha señalado Piaget (Sagesse...), han nacido siempre de una investigación científica realizada por el propio filósofo o por sus contemporáneos, y han culminado en una determinada propuesta de organización social. Entendían también por qué los llamados "problemas” de la filosofía no son permanentes ni existen por sí mismos, y que están traspasados de una fundamental historicidad, que les hace solidarios de las configuraciones culturales en que nacen, aunque a veces se prolongan en otras configuraciones, cambiando, por supuesto, las incógnitas que se proponen despejar.

No es posible, sin embargo, eliminar la sospecha de que aquellos cursos que se parecen a los que estoy proponiendo, nunca llegan a tener los méritos suficientes para ser considerados como cursos de filosofía: en el mejor de los casos llegan a la historia de la filosofía; desde ella, hasta la filosofía misma, media una distancia que no siempre se puede salvar con el estudio de las doctrinas o sistemas del 
pasado o del presente, si ni quiera si se lee directamente a los filósofos en sus propios textos. Muchas veces ha sido el estudio sistemático y profundo de un solo filósofo el que ha abierto la posibilidad de un filosofar propio y original: tal fue, por ejemplo, el caso de Bolívar Echeverría, nuestro compatriota aún desconocido; pero en otros tantos casos el resultado no ha sido favorable.

\section{Y sin embargo...}

El hombre no puede prescindir de la filosofía. Así, ella está presente, siempre viva y en todas partes [...]

La única cuestión que se plantea es la de saber si es consciente o no, buena o mala, confusa o clara. Jaspers, Introduction à la philosophie

Al redactar los párrafos anteriores sabía que mis razonamientos y experiencias no podían conducirme sino a una conclusión que no por breve es menos dramática: "quien no haya alcanzado un real y efectivo dominio de una ciencia, cualquiera que sea -lingüística, matemáticas, física, biología o historia..., o cualquiera de sus derivadas-, no necesita estudiar filosofía: al contrario, hacerlo puede ser perjudicial".

Pero, curiosamente, ahora que he llegado ya a formular tal conclusión no puedo ocultar que me siento incómodo con ella. En primer lugar, es una conclusión que vincula de manera excesiva a la filosofía y la ciencia; en segundo lugar, parece haber olvidado las experiencias de un pensar radical nacido de ciertas situaciones que, a falta de otro nombre, llamaré existenciales, sin que eso signifique adhesión alguna a la filosofía existencialista; en tercer 
lugar, creo que el solo respeto a la tradición no es razón suficiente para explicar la supervivencia de la filosofía; en cuarto y último lugar, pienso que toda negación de la filosofía es tan tautológica como aquella "Nueva refutación del tiempo" que se debe al talento de Borges. Algo me dice que detrás de estos motivos subyace el viejo pleito entre la Razón y la Intuición. Trataré de explicarlos sin intentar siquiera meterme en ese pleito que no tiene salida.

Primero: ¿por qué razón se debería pensar que la filosofía debe estar vinculada a la ciencia y solo a ella? Es cierto que en los confines de la ciencia los más avanzados investigadores empiezan a hacerse preguntas que ya no son científicas, sino filosóficas: un caso ejemplar es el de Stephen Hawkins, cuyas indagaciones sobre el tiempo y el espacio le han llevado a preguntarse incluso por la posibilidad de concebir un ser como el que está aludido con la palabra Dios; pero es evidente que, si nos atenemos a casos como ese, resultaría que el pensar filosófico está reservado a genios como el suyo, o por lo menos para quienes se ocupen en la investigación pura. Por otra parte, el hecho de que la filosofía moderna, a partir de Descartes, haya privilegiado los problemas epistemológicos, no significa que la filosofía deba quedar reducida sin más a epistemología: significa solamente que en los siglos XVI y XVII, cuando la ciencia estaba naciendo, era necesario legitimarla frente al saber teológico, tenido todavía como el único verdaderamente necesario; era preciso — por decirlo brevementedemostrar que, aun admitiendo que Dios ha enseñado a los hombres todo lo que ellos necesitan saber para salvarse, había que entender que esa enseñanza no se encontraba solamente en el libro de Dios, la Sagrada Escritura, sino también en el "gran libro de la naturaleza", que estaba escrito en lenguaje matemático. "Leer" el libro de la naturaleza, por lo tanto, no era contrario a la voluntad de Dios ni implicaba repetir el pecado de Adán... Ingeniosos esguinces, 
desde luego, para afirmar el valor de la Razón sin romper radicalmente con la $\mathrm{Fe}$, y en última instancia con el Poder. Léase a Galileo, por ejemplo, y descúbrase por qué en su tiempo había que preguntarse si es posible conocer y, sobre todo, cómo es posible conocer. Sin embargo, desde entonces ha corrido mucha agua debajo de los puentes, y si bien la ciencia plantea todavía problemas nada fáciles relativos al conocimiento, nadie puede negar que ellos no ocupan la totalidad del campo propio de la filosofía, aunque todo él lo presupone. Para advertirlo bastaría echar un vistazo al estudio de la filosofía contemporánea que ha realizado Manuel Cruz.

Segundo, ¿por qué he de pensar que mis propios fracasos en el intento de provocar en mis alumnos las más radicales reflexiones a partir de sus experiencias vitales, deba convertirse en una regla absoluta para todos los maestros? Evidentemente, que yo haya sido un mal maestro no significa que todos lo sean: por lógica elemental -por honradez también- admito que debe haber, no digo en el mundo sino en mi propia ciudad, muchos maestros de esos que realizan una genuina entrega a sus alumnos, $y$ dotados además no solamente de un conocimiento completo de la filosofía, sino también y principalmente, de aquellos recursos didácticos que yo nunca me preocupé de adquirir. ¿Por qué no he de pensar entonces que tales maestros tocarán constantemente las fibras más íntimas de la sensibilidad de sus alumnos, despertando en ellos esas reflexiones radicales que, como ninguna otra, son una auténtica búsqueda de la verdad, pero no su posesión?

Tercero, ¿por qué pensar que el respeto a una venerable tradición haya sido el único motivo de que en todas las escuelas y universidades de Occidente se conserve la enseñanza de filosofía, pese al predominio que han adquirido las ciencias y la tecnología? Aunque ese respeto ha sido, sin duda alguna, un motivo de peso, y aunque la filo- 
sofía que se ha conservado sea justamente de aquellas que se vinculan más claramente con las ciencias -Frege, Russel, Moore, Wittgenstein, Popper, Ryle, Austin, Strawson...- es posible que existan otros motivos, no siempre los mismos, pero siempre eficaces. Por ejemplo, la necesidad de contar con un instrumento racional que refuerce y consolide los sistemas de creencias religiosas, tal como se practica, en particular, en el mundo católico; o el deseo de fundamentar con nuevos enfoques el estudio de las disciplinas sociales, morales y políticas -Marx, pero sobre todo Horkheimer, Adorno, Habermas, Lévi-Strauss, Foucault, Lacan, Deleuze, Derrida-; o el proyecto de abrir un horizonte nuevo a los estudios lingüísticos, literarios y artísticos cierto Heidegger, Gadamer, cierto Sartre-; o finalmente el intento de entender la condición del presente - Lyotard, Vattimo... Si es verdad que la tradición pesa mucho, también es verdad que cada época se considera a sí misma una cumbre y requiere afirmarse en fundamentos que no sean pasajeros, como los de la ciencia actual, que vive sometida a un replanteamiento constante de sus propios principios. Una necesidad de coherencia, que traspasa todas las instancias de la vida social, quizá no sea ajena a la decisión de conservar en la enseñanza media y superior los cursos de filosofía, a la cual se asigna - a veces tácitamente, a veces de manera expresa - una capacidad única de coordinar valores y expresar la unidad del ser humano, pese a todos los fenómenos que hoy parecen disgregarle. Al fin y al cabo, la humanidad no puede darse el lujo de gastar energías en aquello que es inútil: lo que hace, lo hace siempre por necesidad a no ser -claro- que pensemos exclusivamente en el modo de ser de la sociedad moderna gobernada por el capitalismo, cuya irracionalidad le ha llevado justamente a desarrollar más aquellas actividades que el ser humano menos necesita. 
Cuarto, ¿cómo no se ha de reconocer un verdadero filosofar en todo intento de negar la filosofía? Negarla, en efecto, es privarla de valor; es despojarla de sus títulos y atributos; es desconocer lo que todos los filósofos aportaron a su tiempo; es levantar, conscientemente o no, una teoría, por rústica que sea, acerca del pensar y sus objetos. He oído decir, por ejemplo, que la filosofía no sirve para la vida, porque nunca ha cambiado el mundo ni ha podido mostrar ninguna utilidad; y al oírlo he pensado que solo en nombre de una filosofía utilitarista es posible decir algo semejante. Lo cual, bien mirado, significa que la filosofía está siempre allí, rodeándonos, abrazándonos, penetrando en nuestros juicios y en nuestras miradas, y que está a pesar de nosotros mismos, a pesar de nuestra voluntad.

Esta última idea, sin embargo, necesita ser prudentemente matizada. Como dice Sartre, la Filosofía no existe: no es más que una "sombra de la ciencia", una "eminencia gris de la humanidad", una "abstracción hipostasiada" (Questions de méthode...). Lo que existe es un conjunto de filosofías. O más bien, como agrega él mismo, en cada momento hay una filosofía que se constituye para expresar el movimiento general de la sociedad -del cual forma parte también el quehacer científico-, y mientras ella existe, sirve de "medio cultural" a sus contemporáneos. Por tanto es esa filosofía la que está siempre allí, envolviéndonos, sirviéndonos de trasfondo, dando sentido a nuestros afanes y a nuestras búsquedas, a nuestros hallazgos y nuestros descarríos, a nuestras dudas también, a nuestras valoraciones grandes y pequeñas, a la confianza que solemos poner en cierto orden del mundo que nos parece natural, pero no lo es: en una palabra, esa filosofía que nos sirve de atmósfera y medio cultural.

Pero no olvidemos que, como enseñaba Hegel, la verdad de cada cosa es su contrario (Phänomenologie...): esa filosofía que es nuestro medio cultural, nuestro contex- 
to, nunca es única, puesto que implica también su negación. Quizá por eso, en nuestro tiempo nadie puede prescindir del trasfondo pragmático y utilitario, obviamente materialista, que es propio del capitalismo dominante; pero tampoco del pensamiento que lo denuncia, aunque carece de cualquier posibilidad de realizarse en la historia: el marxismo. No se trata de aceptarlos o no; se trata de que están ahí, invisibles, formando una pareja inseparable. Inevitable también.

Estas conclusiones, que evidentemente contradicen lo que he escrito al comenzar, no lo desmerecen sin embargo. Al contrario, lo ratifican: ya estamos en ese "callejón sin salida" al que conduce siempre el pensar; ya es hora de atravesar los muros para "salir al campo".

Quito, abril 2011

\section{Nota bibliográfica}

No sé si ésta sea propiamente una bibliografía; sé, sin embargo, que algunos libros me han salido al paso mientras componía estos párrafos.

Borges, Jorge Luis

1976 "La muralla y los libros" en: Otras inquisiciones (1960), Madrid: Alianza Editorial.

Cruz, Manuel

2002 Filosofía contemporánea, Madrid: Taurus.

Daval, Simon

1951 Philosophie générale. Classe de Philosophie. Préparation aux Grandes Écoles, París: PUF.

Descartes, René

1963 Discours de la méthode (1637), en: OEuvres et lettres, Bibliothèque de la Pléiade, París: NRF.

Echeverría, Bolívar

2011 Ensayos políticos, Selección e introducción de Fernando Tinajero, Quito, Ministerio de Coordinación Política. 
Galilei, Galilei

1981 Consideraciones y demostraciones matemáticas sobre dos nuevas ciencias, edición preparada por C. Solís y J. Sadaba, Madrid: Editora Nacional.

Hegel, G.W.F.

1966 Phänomenologie des Geistes (1807); hay traducción castellana de Wenceslao Roces, México-Buenos Aires: Fondo de Cultura Económica.

Jaspers, Karl

1989 Introducción a la filosofía (1950), Madrid.

Labastida, Jaime

1969 Producción, ciencia y sociedad: de Descartes a Marx, México: Siglo XXI.

Machado, Antonio

1936 Juan de Mairena. Sentencias, donaires, apuntes y recuerdos de un profesor apócrifo, Madrid.

Marías, Julián

1963 Introducción a la filosofía, Prólogo a las ediciones americana e inglesa (1954), Madrid: Editorial Revista de Occidente.

Nestlé, Wilhelm

1975 Historia del espíritu griego, desde Homero hasta Luciano, traducción castellana de Manuel Sacristán, Barcelona: Ariel.

Piaget, Jean

1965 Sagesse et illusions de la philosophie, Paris: Presses Universitaires de France.

Sartre, Jean Paul

1960 Questions de méthode, en Critique de la raison dialectique, Tome I: Théorie des ensambles practiques, Paris: Gallimard.

Simmel, Georg

1910 Hauptprobleme der Philosophie, Berlin: Gruyter \& Co. 